\title{
Recent UK Retirees' Views About the Work-Related Factors Which Influenced Their Decision to Retire: A Qualitative Study Within The Health and Employment After Fifty (HEAF) Cohort
}

\section{Martin J Stevens}

MRC Lifecourse Epidemiology Unit, Southampton General Hospital, University of Southampton,

\section{Mary Barker}

MRC Lifecourse Epidemiology Unit, Southampton General Hospital, University of Southampton,

\section{Elaine Dennison}

MRC Lifecourse Epidemiology Unit, Southampton General Hospital, University of Southampton,

\section{E. Clare Harris}

MRC Lifecourse Epidemiology Unit, Southampton General Hospital, University of Southampton,

\section{Cathy Linaker}

MRC Lifecourse Epidemiology Unit, Southampton General Hospital, University of Southampton,

\section{Susie Weller}

Clinical Ethics and Law at Southampton (CELS), Faculty of Medicine, University of Southampton

Karen Walker-Bone ( $\boldsymbol{N}$ kwb@mrc.soton.ac.uk)

MRC Lifecourse Epidemiology Unit, Southampton General Hospital, University of Southampton,

\section{Research Article}

Keywords: Retirement, work, ageing

Posted Date: June 3rd, 2021

DOl: https://doi.org/10.21203/rs.3.rs-537101/v1

License: (c) (1) This work is licensed under a Creative Commons Attribution 4.0 International License.

Read Full License

Version of Record: A version of this preprint was published at BMC Public Health on January 17th, 2022. See the published version at https://doi.org/10.1186/s12889-022-12541-1. 


\section{Abstract \\ Background.}

Lower birth rates and increasing longevity have resulted in ageing populations in European countries. These demographic changes place challenges on pension provision as numbers of those who are economically inactive and retired increase relative to those in paid work. Therefore, governments need workers to postpone retirement and work to older ages. Whilst health and wealth are important in retirement decision-making, considerably less is known about the effects of workplace factors. The aim of this study was to explore the views of recent UK retirees about the role that work-related factors played in their decision to retire.

\section{Methods}

This qualitative study was nested within the Health and Employment After Fifty (HEAF) cohort. People who had retired 3-6 years previously (not for health reasons) were purposively sampled to obtain the views of men and women from a range of socio-economic backgrounds and jobs. Semi-structured interviews were carried out by telephone using a pre-defined topic guide. Interviews were audio-recorded, transcribed and analysed thematically.

\section{Results}

Seventeen interviews were conducted. Thematic analysis showed that retirement decisions were complex and multi-factorial but that work-related factors contributed to decision-making in two main ways. First, some work factors pushed participants towards retirement. These were perceptions that: workplace change had affected the way they were valued or increased pressure on them; work demands, including commuting, had intruded excessively on personal time, effects that were exacerbated by modern technology; work was draining, isolating or under-appreciated; and /or that work was causing physical strain or discomfort relative to their perception of their capacity. In contrast, work factors could also cause participants to pull back towards work, particularly: autonomy; supportive work colleagues; a sense of being appreciated; and perceived job flexibility.

\section{Conclusions}

Recent retirees explained that their decision to retire was multi-factorial but work-related factors contributed importantly. Potentially, employers could: review workers' perceptions about their work; their capacity in relation to job demands; increase flexibility; and facilitate a supportive work community to encourage longer working lives. 


\section{Background}

The population of European countries has aged whilst birth rates have declined, re-shaping demographics. The Organisation for Economic Co-operation and Development (OECD) predicts that the old age to working age ratio (i.e. the ratio of people aged $>65$ years $/ 100$ people aged $20-64$ years), which was 13.9 people in 1950 , will rise to 53.4 by $2050^{1}$. Whilst life expectancy has increased, effective ages of retirement in OECD countries has decreased from the 1970s to early $2000 \mathrm{~s}^{2}$. Although this trend has reversed somewhat since, the number of years that individuals spend in retirement has risen overall. This dual effect of increased longevity and earlier retirement has the potential to place strain on pension systems and the wider economy.

Consequently, most high-income countries have taken steps to encourage people to work to older ages ${ }^{3}$ 'a generalized shift from 'pro-retirement' to 'pro-work"4. This includes a rise in the state pension age (SPA), which, in the UK, is in the process of increasing from 60 years (women) and 65 years (men) to 68 years for both sexes ${ }^{5,6}$. This, along with the abolition of mandatory retirement in $2011^{7}$, formed part of a portfolio of changes aimed at encouraging working to older ages and making retirement more of a personal choice.

Given these changes, it is unclear what will determine the decision to retire in forthcoming generations. Health is known to be a key factor determining early retirement. ${ }^{8,9}$ However, the relationship between health and retirement is not unidirectional, since people in good health, and particularly those in better socio-economic circumstances, also tend to take early retirement. ${ }^{10,11}$. Financial wellbeing is another important but complex factor, greater financial security may enable earlier retirement ${ }^{4,10}$ but, conversely, individuals with higher incomes may also delay retirement. 4, 10

Therefore, if the aim is to lengthen working lives, interventions to improve health or increase financial security, although welcome, may not create the desired effect. From the perspective of employers and policy-makers, however, work-related factors that influence retirement decisions could be a relatively straightforward target for interventions to encourage working to older ages. Therefore, as part of a mixedmethods retirement study, we conducted qualitative interviews with contemporary retirees in order to investigate what work-related factors had influenced their retirement decisions and what might have supported them to remain at work, whilst also permitting a wider exploration of factors influencing retirement that may not have been anticipated.

\section{Methods}

\section{Sampling}

This study was nested within the Health and Employment After Fifty (HEAF) study, a prospective cohort study incepted in England, UK, between 2013 and 2014 to investigate work and health amongst people aged 50-64 years (the detailed methodology is described elsewhere) ${ }^{12}$. For the current study, eligible 
HEAF participants comprised those who reported at baseline that they were 'retired', who had stopped working within the past 24 months and who had not left work for a health reason. Participants who were unemployed leading up to retirement were also excluded. Sampling was purposive, based upon socioeconomic status (defined by the National Statistics Socio-economic Classification three-class system $^{13}$ ) and sex.

Eligible retirees were sent a participant information sheet with a consent form and pre-paid return envelope. Upon receipt of written consent, willing participants were contacted by telephone at a time convenient to them. Telephone interviews were chosen in order to keep the sample as inclusive as possible (participants live across England) and to make it as easy as possible for potential participants (telephone interviews have been shown to be less daunting and intrusive than in-person interviews ${ }^{14}$ ). There was no reward for, or inducement to, participate.

\section{Data collection}

A topic guide was drawn up in advance, taking into account that the decision to retire is multifactorial ${ }^{15}$ and that non-work factors are also relevant. Initially, open questions were asked so as to allow participants to raise any issues pertinent to their personal retirement decision. The topic guide then focussed on the possible role of work factors in retirement, informed by findings from previous studies ${ }^{9}$, 16,17 , and reflecting psychosocial work strain models ${ }^{18-20}$. Questioning covered: workload/effort; rewards, training and skills; control; environment; job satisfaction; and work community. The topic guide was tested with two practice telephone interviews with volunteers but no changes were required.

Interviews were conducted by MJS, a 38-year-old man undertaking a PhD, trained in qualitative methods and interview skills, who had worked as research assistant on the HEAF study for three years. Consent was re-confirmed verbally before interviews commenced. MJS conducted the interviews in a private office and with participants' consent, all were audio-recorded. Participants were usually at home and alone to the best of the researcher's knowledge, although two interviews were interrupted and recommenced after a short break. MJS introduced himself and explained his role. Interviewees understood that MJS was not of retirement age, although this was never expressly stated. Field notes were recorded after each interview and used to aid interpretation of the interview data.

\section{Data processing and analysis}

Interviews were transcribed within three days by MJS. Transcripts were checked against recordings for accuracy but were not returned to the participants for comment. All identifying material was removed from the transcripts and pseudonyms used throughout. Data were analysed thematically ${ }^{21}$ taking a critical realist epistemological stance as described by Maxwell. ${ }^{22}$. Thematic analysis was conducted using Nvivo $11^{23}$ software.

Coding commenced alongside data collection, allowing monitoring of data saturation. Data from three of the interviews were independently and inductively coded by two authors (MJS and KWB) and results 
compared. A coding frame was developed and subsequently applied to all interviews. New codes were added to the coding frame as required and were described using illustrative quotations.

Candidate themes were derived from the data by grouping similar codes together. This process commenced after 13 interviews were fully coded to enable discussion with the wider research team. The candidate themes and updated coding frame were further tested by KWB and MJS through double-coding of three further interviews. Results were then compared, discrepancies discussed/resolved and candidate themes updated.

Interviews were conducted until saturation of themes relevant to the research question was attained. Saturation was defined as the point at which no new codes had been generated in three consecutive interviews for the range of possible work-related factors. ${ }^{24}$

\section{Results}

In total, $58 \mathrm{HEAF}$ participants were contacted, of whom 18 (31\%) agreed to participate. Only seventeen interviews were included in the analysis, however, since one participant reported unemployment prior to retirement. Participants retired between 2012 and 2014 at ages 55-67 years (therefore before, at, and after SPA) (Table 1). At the time of interview, in 2018, participants had been retired for between 3 and 6 years. The interviews lasted between 15 and 30 minutes, excluding introductions and post-interview conversations.

Table 1

Characteristics of participants in the HEAF FIRST qualitative study

\begin{tabular}{|llll|}
\hline & $\begin{array}{l}\text { Men } \\
\text { N=8 }\end{array}$ & $\begin{array}{l}\text { Women } \\
\text { N=9 }\end{array}$ & $\begin{array}{c}\text { Total } \\
\text { N=17 }\end{array}$ \\
\hline Socio-economic status (SES) & & & \\
\hline Higher and managerial & 2 & 3 & 5 \\
\hline Intermediate & 4 & 3 & 7 \\
\hline Routine and manual & 2 & 3 & 5 \\
\hline Employment status prior to retirement & & & \\
\hline Self-Employed & 2 & 4 & 6 \\
\hline Employed & 6 & 5 & 11 \\
\hline Retirement timing & & & \\
\hline Before state pension age & 5 & 2 & 7 \\
\hline At state pension age & 2 & 3 & 5 \\
\hline Later than state pension age & 1 & 4 & 5 \\
\hline
\end{tabular}


Participants' responses were organised into 44 codes and five themes. (Fig. 1). Three of these themes, entitled 1:'Work was pushing me' 2:'It's not you it's me', and 3:'I had my reasons,' described factors that pushed ${ }^{25}$ the participant towards retirement (Fig. 2). 1:'Work was pushing me' captured work-related factors that participants felt had pushed them to retire and was divided into a further four sub-themes. Theme 4: 'But work also pulled me back' included work factors that participants described as discouraging retirement. Theme 5: 'Now I'm free' covered perceptions of life in retirement.

Since our aim was to elucidate the work-related factors that affected retirement decision-making, the following section focuses on the themes 1:'Work was pushing me' and 4:'But work also pulled me back'.

\section{Work was pushing me}

Participants described a range of workplace factors that they viewed as having 'pushed' them towards retirement. These 'push' aspects were negative and/or unpleasant and participants described retirement as allowing them to remedy or escape these effects. This theme consisted of four sub-themes described below:

\section{1(a) You've changed}

Within this sub-theme, we grouped instances of where participants described workplace changes precipitating negative feelings. In some cases, workplace changes resulted in a new work environment, conditions or processes that retirees contrasted unfavourably with previous circumstances. Lisa said that she felt change had made her less valued. When asked what had changed, she replied:

'I think the focus on the service changed. It was not anymore about giving a gold-standard service. In my opinion it was about delivering... volume'

Like Lisa, some participants felt that workplace changes resulted in declining standards and/or increasing workloads, which conflicted with personal values or work-related pride, causing an imbalance for which the only solution was perceived to be retirement. Philip stated that upcoming changes to his workplace (a school) were his main reason for retirement. When asked to describe those changes, he said:

'The sort of changes were cutback in financial support for the services we were providing and not being able to do the job that we... were employed for originally and it was being imposed upon us and it wasn't good for the children.'

However, change was not always perceived negatively. When summarising his experiences near the end of an interview, Gareth said:

'I love new things and challenges but you want to know that you have a secure position within that.'

\section{1(b) Grinding me down}


In this sub-theme, participants described aspects of their work that had become less bearable, (e.g. draining and competitive with heavy workloads) which had gradually pushed participants towards retirement. When asked if he enjoyed his job, Jamie replied:

'Yes I would overall... until, as I say, the point it got a bit much... it was repetitive like that and the complaints got worse... over the years as well and the number of them, volume of them.'

Within this sub-theme, participants perceived a lack of appreciation for their efforts. When asked whether her skills were valued in the workplace, Elena replied:

'Well I think everyone sort of appreciated to a certain extent that actually you were doing a good job with the best you could, or the other staff did but, as much as appreciation from the hierarchy well... some of them stayed in their offices they didn't really get involved too much.'

This sub-theme also included perceptions of being isolated at work. When Jamie was asked what he disliked about his job, he replied:

'Well there was a certain amount of pressure. I was the only one in the office sometimes. You had to deal with everything that came up... and that led to the stress... There wasn't a lot of backup.'

\section{1(c) I've got no time}

In this sub-theme, participants described work as a time-burden or restriction, which caused fatigue and prevented them from engaging in other more meaningful activities. Participants felt that excessive/increased hours infringed upon their personal time. When asked about her main reason for retirement, Betty said:

'I was working a six-day week, not normal hours and it was usually a minimum of 60 hours... sometimes more... To be honest I don't want to work those sort of hours when I'm in my 60s.'

Additionally, within this sub theme, commuting to and/ or from work was regarded as an increasing burden as the participant neared retirement. Gerard's commute made him question his role:

'There was a lot of driving time involved and as I say... the fact that I was spending what seemed to be an inordinate amount of time traveling, that was one of the reasons for saying, 'well why am I doing this?"

Communication technology seemed, to some, to represent a growing burden, such that participants felt they were effectively constantly available for work, which further encroached upon personal time.

Retirement seemed to offer alleviation from these restrictions. Julian described the moment he chose to retire:

'I was at the hospital waiting to go into the operation and I was dealing with e-mails and phone calls and it suddenly struck me that this was not a way... that I wanted to live the rest of my life.'

\section{1(d) This hurts}


Within this sub-theme, participants reflected on the relationship between physical comfort and work. Physical workloads that were previously normal became more unpleasant and unduly burdensome, as the participant neared retirement, sometimes even if the work was otherwise enjoyable. When asked to summarise her retirement decision, Louisa responded:

'I think it's got to be summed up in one word: pain. I was fed up with the pain... although I had so much good things, there were so many good things about it, the pain overrode everything.'

In general, the mismatch between physical work demands and declining physical abilities was described as a personal shortcoming by participants, rather than an imbalance that could be potentially rectified through work modification. In some cases, the physical work environment (unhealthy, unpleasant) pushed individuals towards retirement. Leo was asked whether physical workload influenced his decision to retire, he responded:

'I always felt that obviously doing a lot of heavy lifting and pulling and pushing, sledge-hammering was partly good because it kept me fit but at the same time..., as I got older things were making me a bit out of breath and I could see it was making me, bit unhealthy at the same time. So I decided to knock it on the head.'

\section{But work also pulled me back}

In contrast, we identified a theme in which work-related factors appeared to weigh against the decision to retire. These factors acted as counters to the more negative 'push' aspects of work described above. Participants described work as providing many positives, including a sense of pride and status. Some reported perceiving work as a break from the rigours of outside life. Participants reported that having supportive colleagues formed a community both in and outside work. Loyalty to this community and unease at the prospect of leaving it seemed to make retiring more difficult. When discussing colleagues' influence on her retirement decision, Alice said:

'I didn't feel I could just walk away. That wouldn't be fair to somebody you worked with for 25 years.'

This theme also captured opportunities for the negative 'push' aspects of work to be mitigated e.g. by having autonomy and/or being appreciated. Greg, a factory worker, described his workplace as increasingly complex. When asked whether this had influenced his retirement decision, he replied:

'No, because basically the involvement I had from, well day one, meant I was part of the process.'

Some participants described how flexibility in working hours acted as a pull towards work. Patsy described a situation where her partner had become seriously ill:

'I had time off and if I wanted to I could've worked from home and just when he came out of hospital. Things like that, they were... very good. But I managed to go back after about two or three weeks on a part-time basis and then went back full-time later on.' 


\section{Other themes}

Two other themes included factors that pushed participants towards retirement but were notionally unrelated to the workplace. In theme 2:'It's not you it's me', the push towards retirement came from personal values or feelings, rather than being generated by external circumstances. For example, participants suggested that there was a 'normal' age to retire or a point at which retirement was almost inevitable. In theme 3:'I had my reasons', factors pushing towards retirement seemed to be external to the participant or were outside of their control. These factors acted upon the participant and changed their plans. Health status and financial status pushed the participant towards retirement, whilst caring responsibilities and family interactions were also prime motivators. The fifth theme, 'Now I'm free', encompassed descriptions and perceptions of life in retirement. Retirement was often described in terms of freedom, which was a counterpoint to the restrictions of their job, providing an escape from the negative aspects of work or other push factors.

\section{Discussion}

Using qualitative methods, we researched the views of men and women, employed in a range of jobs, about their decision to retire 3-6 years earlier (excluding those who retired for health reasons). We invited participants to tell their own stories and contextualise their retirement decisions by describing every aspect. This was important because for the most part, the decision to retire was multi-factorial. Consequently, some of the reasons participants gave for retirement were not work-related. We found considerable evidence, however, that work-related factors played a role in participants' decision-making and that these influences acted to both 'push' them away from work or 'pull' them back towards it.

Participants gave examples of how potentially negative aspects of their work could be effectively countered by positive features, even though participants eventually all decided to retire. For example, workplace change appeared to have contributed importantly to several retirees' decisions, particularly when changes were perceived as leading to declining standards or higher work demands. Equally, however, a participant who felt fully involved in workplace change explained that the change had not pushed him towards retirement because his employers had engaged him in the change process. In some cases, participants seemed to become less able to tolerate aspects of their job (e.g. working in isolation) so that they felt it 'grind them down' and push them away. It seemed the retirees became less inclined to accept work-related time-burdens as they neared retirement, so that excessive hours, long commutes or being available out of hours became more of a 'push' to retire. Another factor of importance was a perceived mismatch with the physical demands of the work, especially when coupled with a corresponding self-perceived decline in their resilience or capability, for which participants tended to feel personally responsible. In mitigation, however, retirees described several factors that pulled them to continue working, such as supportive relationships with colleagues, a feeling of being appreciated, and flexible hours. 
Our finding that physically-demanding work was more difficult to sustain at older ages was previously reported in another qualitative study undertaken in the Netherlands ${ }^{17}$. Interestingly, however, a number of quantitative studies exploring the same question have been inconclusive ${ }^{15,26-28}$. Our data do however highlight that the physical nature of an individual's work only became important to retirement decisions when accompanied by a corresponding perceived decline in physical capabilities. Numerous retirement studies ascertain the frequency, intensity and duration of physical work demands, but it may be more relevant to understand how older workers perceive they are coping with the physical demands of their work and thus explore any change in an individual's capacity or resilience to meet these work demands. This also has implications for longitudinal studies that measure self-reported workload at baseline as a risk factor for retirement several years subsequently. If it is not the demands of work itself but the change in capacity or resilience to meet the demands that matters, then the point may be being missed. If this hypothesis stands up, employers seeking to retain older workers may be advised to introduce regular performance or career reviews with older workers to take into account their perceptions about the match between their changing physical capacity and the work demands. Muscle mass and strength are known to peak at around $30-40$ years of age ${ }^{29}$ after which there is a general decline. Whilst experience can mitigate these effects, it is unrealistic to expect older workers to retain exactly the same capacity throughout their working life. Employers and policy-makers need to consider options for redeployment or re-training or be prepared to accommodate the changes in physical function and resilience of older workers.

That older workers begin to resent the incursion of their work on their personal time more as they near retirement is perhaps not unexpected but is important. Sewdas ${ }^{30}$ previously identified flexible working practices as a pre-condition for maintaining longer working lives and flexibility is probably the solution which best enables the individual to balance changing priorities. Our study highlights commuting times, long working hours, working in isolation and an expectation that workers should be available out of hours as some key issues that employers could address using innovative solutions to reduce the perceived incursion on personal time, thereby enabling prolonged working.

Our data demonstrate that retirement decisions are multifactorial in line with prior studies ${ }^{17}$. Financial considerations and health were reported by participants as relevant to their retirement decisions. Our focus on work factors was chosen to better understand what, in the context of people's health and financial circumstances, might be modified to encourage working to older ages. Our findings of the importance of factors such as: having supportive working colleagues; autonomy in the workplace; flexible hours; and appreciation at work highlights areas in which employers could focus attention in order to retain older workers. Importantly however, these factors are known to be important amongst workers of all ages and have been captured by a variety of different models of work stress ${ }^{18,19}$. Work stress is associated with impaired mental and physical health cross-sectionally and longitudinally ${ }^{31-33}$ and measures to reduce these impacts should be encouraged for workers of all ages, rather than singling out older workers alone for such initiatives, which may encourage age discrimination and may be perceived by the workers themselves as devaluing them as a group, as suggested in prior research. ${ }^{34}$ 
Our findings need to be considered alongside some limitations. The participants had retired some 3-6 years ago. It is feasible that recollections of retirement decisions may have changed over time and that they may have reported different determinants had we been able to interview them contemporaneously. It is not clear whether the passing of time would make perceptions of former workplaces more, or less, favourable. Although participants generally reported enjoying their retirement, they still had fond recollections of work, despite frustrations which had contributed to their retirement. Importantly, as they had all chosen to retire, the factors reported as pulling participants back towards work had not persuaded them to continue working. It may not necessarily be possible to extrapolate our findings to adults working beyond SPA. However, 5 of the 17 participants in the current study had worked beyond their SPA, so the factors reported here were at least of some relevance to longer working lives.

We cannot rule out participation bias. The invitation explained that the interview would explore retirement decisions and work conditions prior to retirement and it is possible that those who had retired for workrelated reasons may have been more likely to respond. However, the overall sampling frame of the HEAF study was from general practice registers, recognised to be almost exactly representative of the general population. Furthermore, retirement was not emphasised in the original HEAF study aims.

Our study has particular strengths. Our participants are among the first individuals in the UK who retired after the implementation of government measures, including increase in the SPA and abolition of mandatory retirement, intended to encourage working to older ages. Women participating in this study were also subject to incremental changes in the SPA ${ }^{5}$ which were rolled-out throughout the period during which they made their retirement decisions. Therefore, our study explored a wide range of work and retirement factors that individuals viewed as important to them when making voluntary retirement decisions in a contemporary context. Furthermore, the HEAF study includes inhabitants from all over England and from all 10 deciles of deprivation and we chose to purposively sample women and men from across the socio-economic spectrum, and additionally included individuals who retired before, at, and, (nearly $30 \%$ of the sample) after SPA.

\section{Conclusions}

Amongst recently-retired English workers, the interaction of work and personal factors along with the individual's own perceptions were decisive in the balance of pushes and pulls that tipped the participants towards their retirement decision. The work factors identified could be addressed by practical interventions to support people who wish to continue working to do so in comfort and good health, potentially lengthening working lives. This qualitative work has also highlighted new areas of questioning for a case-control study on retirement decisions which will also be nested within the HEAF cohort.

\section{List Of Abbreviations}

HEAF The Health and employment after 50 study 


\section{Declarations}

\section{Ethics approval and informed consent to participate}

Ethics approval was obtained from NHS Health Research Authority, North West, Liverpool East Research Ethics Committee, IRAS project ID 103258, REC Reference 12/NW/0500, substantial amendment (no.7)

17 January 2018. Informed consent was obtained from all the participants involved in the study. Written consent to participate was obtained from all participants and re-affirmed verbally before interview. The study was carried out in accordance with ethical guidelines of the University of Southampton and the 1964 Helsinki declaration

\section{Consent for publication}

Not applicable.

\section{Availability of data and materials}

The dataset generated and analysed during the current study are available from MJS but restrictions apply to the availability of these data, which were used under license for the current study, and so are not publicly available. Data are however available from the authors upon reasonable request and with permission of KWB.

\section{Competing interests}

The authors declare that they have no competing interests.

\section{Funding}

This work was supported by grant CF/02/17 from The Colt Foundation.

\section{Authors' contributions}

MJS, MB, ECH, ED, CL and KWB were responsible for study design and development of the topic guides. Interviews and transcriptions were carried out by MJS. Data analysis was carried out by MJS, KWB, MB, and SW. MJS wrote the first draft of the paper. All authors contributed to the writing of subsequent drafts and have approved the final draft.

\section{Acknowledgements}

We would like to thank the HEAF cohort, especially those who agreed to be interviewed for this study.

\section{References}


1. OECD. "Demographic Old-Age to Working-Age Ratio", in Pensions at a Glance 2019: OECD and G20 Indicators, https://doi.org/10.1787/e2839a52-en. : OECD Publishing, Paris; 2019.

2. OECD. Average effective age of retirement in 1970-2017 in OECD countries2019. Available from: http://www.oecd.org/els/emp/average-effective-age-of-retirement.htm.

3. OECD. OECD, Recommendation of the Council on Ageing and Employment Policies, OECD/LEGAL/0419 https://www.oecd-ilibrary.org/content/publication/9789264035881-en2015.

4. Topa G, Depolo M, Alcover CM. Early Retirement: A Meta-Analysis of Its Antecedent and Subsequent Correlates. Front Psychol. 2017;8:2157.

5. Pensions Act 1995, Stat. c.26 (1995).

6. Pensions Act 2007, Stat. c.22 (2007).

7. The Employment Equality (Repeal of Retirement Age Provisions) Regulations 2011, (2011).

8. van Rijn RM, Robroek SJ, Brouwer S, Burdorf A. Influence of poor health on exit from paid employment: a systematic review. Occup Environ Med. 2014;71(4):295-301.

9. van den Berg TI, Elders LA, Burdorf A. Influence of health and work on early retirement. J Occup Environ Med. 2010;52(6):576-83.

10. Fisher GG, Chaffee DS, Sonnega A. Retirement Timing: A Review and Recommendations for Future Research. Work, Aging and Retirement. 2016;2(2):230-61.

11. de Wind A, Geuskens GA, Reeuwijk KG, Westerman MJ, Ybema JF, Burdorf A, et al. Pathways through which health influences early retirement: a qualitative study. BMC Public Health. 2013;13:9.

12. Palmer KT, Walker-Bone K, Harris EC, Linaker C, D'Angelo S, Sayer AA, et al. Health and Employment after Fifty (HEAF): a new prospective cohort study. BMC Public Health. 2015;15:1071.

13. Statistics OfN. The National Statistics Socio-economic classification (NS-SEC).

14. Weller S. Using internet video calls in qualitative (longitudinal) interviews: some implications for rapport. International Journal of Social Research Methodology. 2017;20(6):613-25.

15. de Wind A, Geuskens GA, Ybema JF, Blatter BM, Burdorf A, Bongers PM, et al. Health, job characteristics, skills, and social and financial factors in relation to early retirement-Results from a longitudinal study in the Netherlands. Scand J Work Environ Health. 2014;40(2):186-94.

16. Scharn M, Sewdas R, Boot CRL, Huisman M, Lindeboom M, van der Beek AJ. Domains and determinants of retirement timing: A systematic review of longitudinal studies. BMC Public Health. 2018;18(1):1083.

17. Reeuwijk KG, de Wind A, Westerman MJ, Ybema JF, van der Beek AJ, Geuskens GA. 'All those things together made me retire': qualitative study on early retirement among Dutch employees. BMC Public Health. 2013;13:516.

18. Karasek RA. Job Demands, Job Decision Latitude, and Mental Strain: Implications for Job Redesign. Administrative Science Quarterly. 1979;24(2):285-308.

19. Siegrist J, Starke D, Chandola T, Godin I, Marmot M, Niedhammer I, et al. The measurement of effortreward imbalance at work: European comparisons. Soc Sci Med. 2004;58(8):1483-99. 
20. Leiter MP, Maslach C. Six areas of worklife: a model of the organizational context of burnout. J Health Hum Serv Adm. 1999;21(4):472-89.

21. Braun V, Clarke V. Successful qualitative research: A practical guide for beginners: sage; 2013.

22. Maxwell JA. A realist approach for qualitative research: Sage; 2012.

23. NVivo qualitative data analysis software: QSR International Pty Ltd. Version 11; 2015.

24. Fusch PI, Ness LR. Are We There Yet? Data Saturation in Qualitative Research. Qualitative Report. 2015;20(9):1408-16.

25. Shultz KS, Morton KR, Weckerle JR. The Influence of Push and Pull Factors on Voluntary and Involuntary Early Retirees' Retirement Decision and Adjustment. J Vocat Behav. 1998;53(1):45-57.

26. Topa G, Moriano JA, Depolo M, Alcover C-M, Morales JF. Antecedents and consequences of retirement planning and decision-making: A meta-analysis and model. J Vocat Behav. 2009;75(1):3855.

27. Lund T, Villadsen E. Who retires early and why? Determinants of early retirement pension among Danish employees 57-62 years. Eur J Ageing. 2005;2(4):275-80.

28. Carr E, Hagger-Johnson G, Head J, Shelton N, Stafford M, Stansfeld S, et al. Working conditions as predictors of retirement intentions and exit from paid employment: a 10-year follow-up of the English Longitudinal Study of Ageing. Eur J Ageing. 2016;13:39-48.

29. Dodds RM, Syddall HE, Cooper R, Kuh D, Cooper C, Sayer AA. Global variation in grip strength: a systematic review and meta-analysis of normative data. Age Ageing. 2016;45(2):209-16.

30. Sewdas R, de Wind A, van der Zwaan LGL, van der Borg WE, Steenbeek R, van der Beek AJ, et al. Why older workers work beyond the retirement age: a qualitative study. BMC Public Health. 2017;17(1):672.

31. Lang J, Thomas JL, Bliese PD, Adler AB. Job demands and job performance: the mediating effect of psychological and physical strain and the moderating effect of role clarity. $\mathrm{J}$ Occup Health Psychol. 2007;12(2):116-24.

32. Theorell T, Hammarstrom A, Aronsson G, Traskman Bendz L, Grape T, Hogstedt C, et al. A systematic review including meta-analysis of work environment and depressive symptoms. BMC Public Health. 2015;15:738.

33. Theorell T, Jood K, Jarvholm LS, Vingard E, Perk J, Ostergren PO, et al. A systematic review of studies in the contributions of the work environment to ischaemic heart disease development. Eur J Public Health. 2016;26(3):470-7.

34. Hennekam S, Herrbach 0 . The influence of age-awareness versus general HRM practices on the retirement decision of older workers. Personnel Review. 2015;44(1):3-21.

\section{Figures}




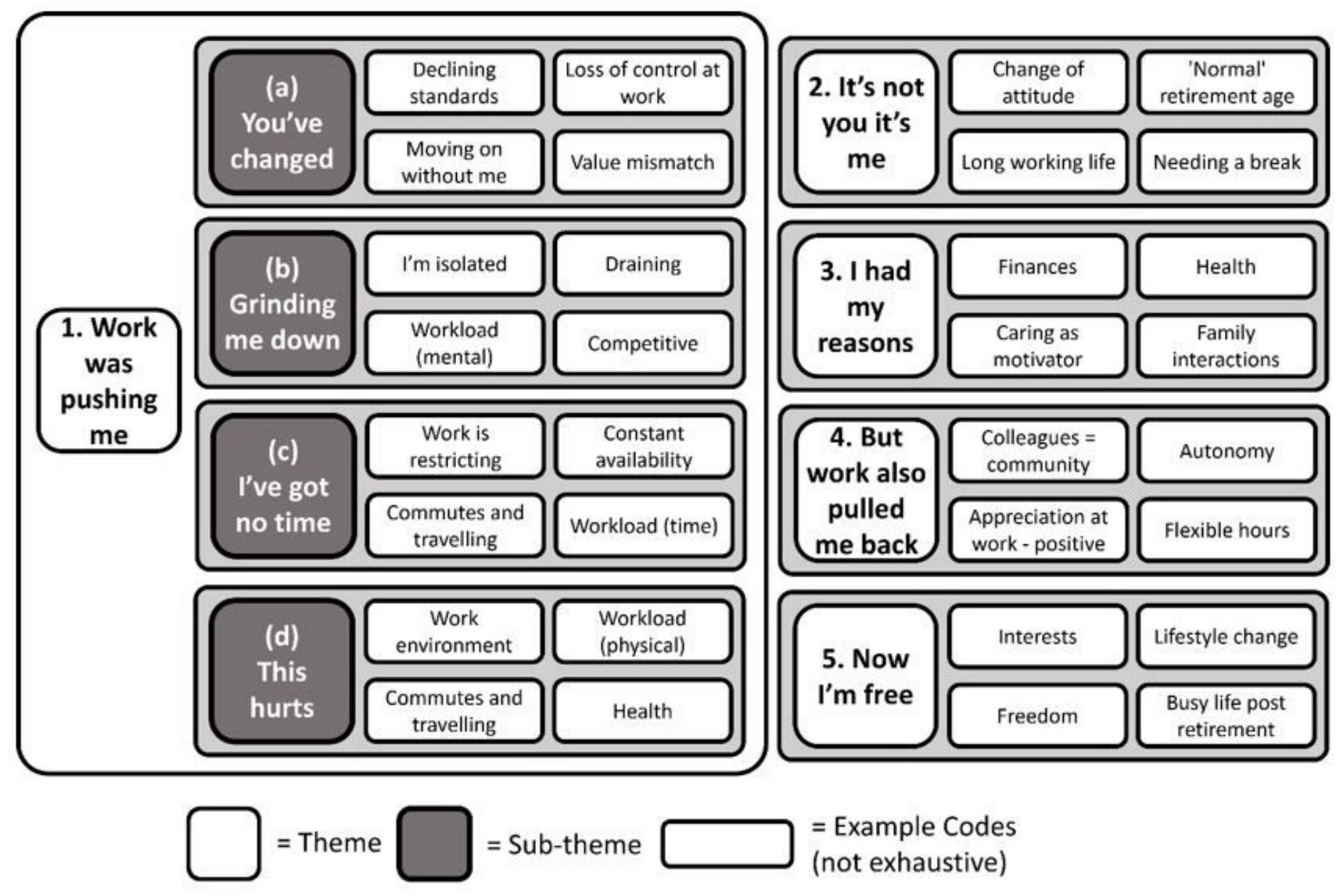

Figure 1

Summary of the codes and themes derived after thematic analysis of the 17 interviews 


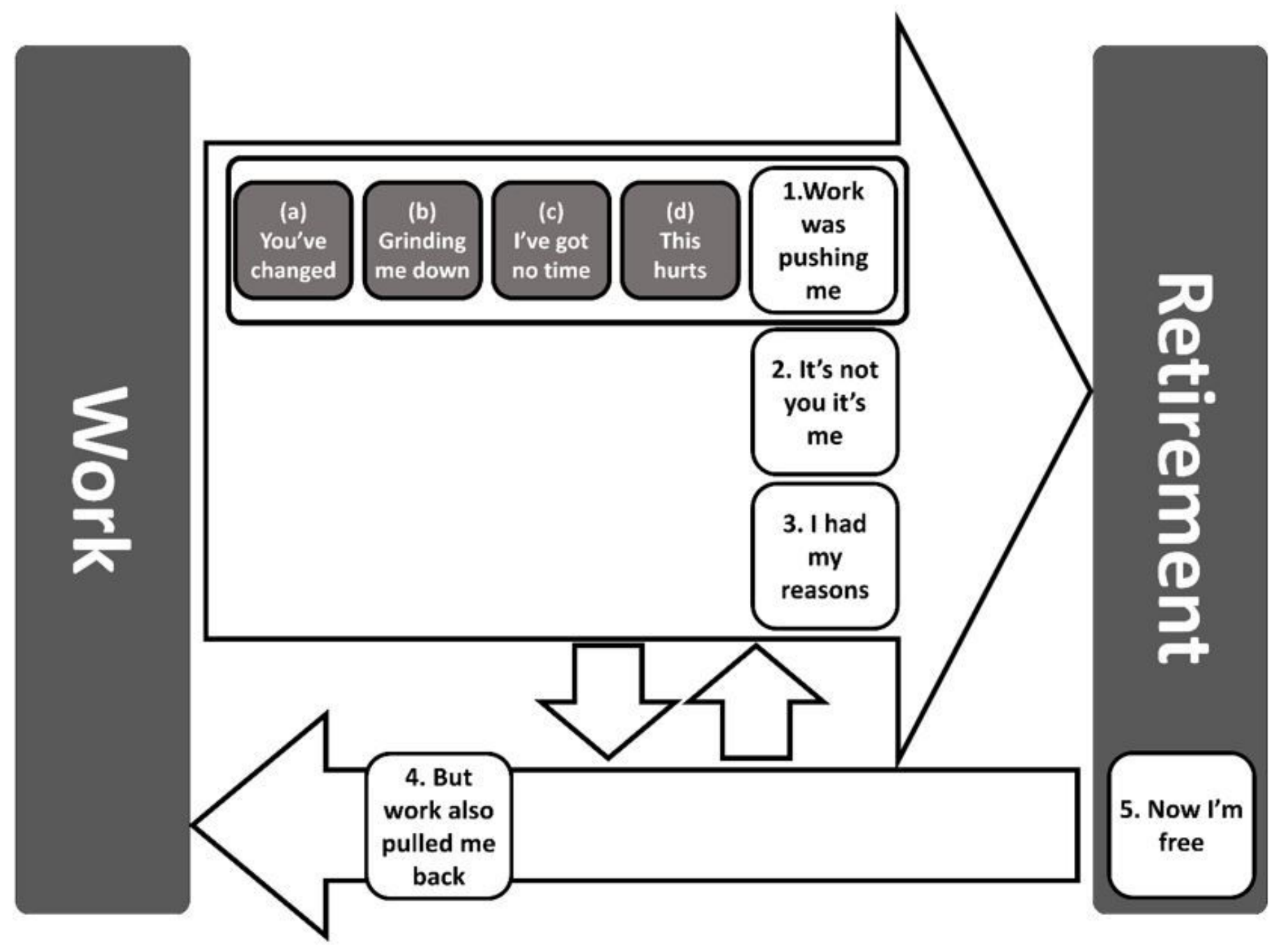

Figure 2

Thematic map of the HEAF FIRST qualitative study 